\section{RICYDE. Revista Internacional de Ciencias del Deporte doi: $10.5232 /$ ricyde \\ Rev. Int. cienc. deporte}

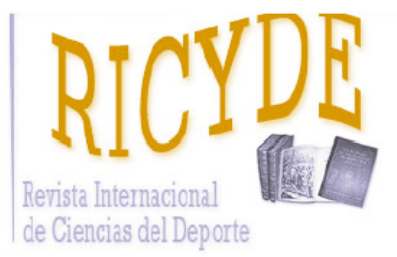

RICYDE. Revista Internacional de Ciencias del Deporte Volume XV - Year XV

Pages: 35-54 - ISSN: 1885-3137

Issue 55 - January 2019

\title{
The new version of the pictorial scale of Perceived Movement Skill Competence in Spanish children: Evidence of validity and reliability \\ La nueva versión de la escala pictográfica de Percepción de Competencia de Habilidades Motrices in niños y niñas españoles: Evidencias de validez y fiabilidad
}

\author{
Isaac Estevan ${ }^{1}$, Javier Molina-García ${ }^{1}$, Ana Queralt ${ }^{2}$, Steve J. Bowe ${ }^{3}$, Gavin Abbottt ${ }^{4}$ Lisa M. Barnett ${ }^{5}$
}

1. AFIPS Research Group. Department of Teaching Music, Visual and Corporal Expression. University of Valencia, Valencia, Spain.

2. AFIPS Research Group. Department of Nursing. University of Valencia, Valencia, Spain.

3. Deakin Biostatistics Unit, Faculty of Health, Deakin University, Geelong, Australia.

4. Institute of Physical Activity and Nutrition, School of Exercise and Nutrition Sciences. Deakin University, Geelong, Australia.

5. Institute of Physical Activity and Nutrition, School of Health and Social Development. Deakin University, Geelong, Australia.

\begin{abstract}
The purpose of this study was to i) examine reliability and construct validity of the pictorial scale of Perceived Movement Skill Competence (PMSC) aligned to the third version of the Test of Gross Motor Development (TGMD-3) in a sample of Spanish children; and to ii) analyse the validity of the PMSC and children's perceived motor competence (MC) according to gender. A convenience sample of 361 children ( $55.7 \%$ boys) between 4 and 11 years-old participated. The pictorial scale of PMSC (19 items) was administered (a random subsample repeated the PMSC twice). Test-retest reliability using Intraclass Correlation Coefficients and construct validity using a Bayesian Structural Equation Modeling approach were conducted in each subscale and the total PMSC. High to excellent reliability was found. The two-factor model with non-informative cross-loadings and informative cross-loadings were both adequate fitting models. Boys reported a higher perception in ball skills, locomotion and the total PMSC than girls $(p<.05)$. These findings provide evidence of the construct validity and reliability of the two-factor PMSC aligned with the TGMD-3 in locomotion and ball skills. The Spanish version of the pictorial scale of PMSC would be useful for assessing perceived MC in Spanish children, something in particular interest for Physical Education teachers.
\end{abstract}

Key words: motor competence; self-concept; gender; childhood; Bayesian analyses.

\section{Resumen}

El objetivo de este estudio fue i) analizar la fiabilidad y validez de constructo de la escala pictográfica de Percepción de la Competencia Motriz (PMSC) alineada con la tercera versión del Test de Competencia Motriz Gruesa (TGMD) en una muestra de niños y niñas españoles y ii) analizar la validez de la PMSC y la percepción de competencia motriz (CM) de esos niños y niñas en función del género. Participó una muestra por conveniencia de 361 niños y niñas (55,7\% niños) de entre 4 y 11 años de edad. Se administró la escala pictográfica PMSC (19 ítems) y una muestra aleatoria la realizó dos veces. En cada subescala y la escala PMSC total se analizó la fiabilidad test-retest y la validez de constructo utilizando el coeficiente de Correlación Intraclase y Modelos de Ecuaciones Estructurales de Bayes. Los resultados de la fiabilidad fueron entre altos y excelentes. Los modelos de dos factores con cargas cruzadas, informativas, y no informativas, mostraron buenos ajustes. Según el género, los niños puntuaron más alto en percepción de habilidades de balón, de locomoción y la PMSC total que las niñas ( $p$ $<, 05)$. Estos resultados ofrecen evidencias de validez de constructo y fiabilidad de los dos factores de la PMSC alineados con el TGMD-3 en habilidades de locomoción y balón. La versión en castellano de la escala pictográfica PMSC parece ser útil para estudiar la percepción de CM en niños y niñas españolas, cuestión interesante para los docentes de Educación Física.

Palabras clave: competencia motriz; auto-concepto; género; niñez; análisis de Bayes.

Correspondencia/correspondence: Isaac Estevan

AFIPS Research Group. Department of Teaching Music, Visual and Corporal Expression. University of Valencia, Valencia, Spain.

Email: isaac.estevan@uv.es 
Estevan, I.; Molina-García, J.; Queralt, A.; Bowe, S. J.; Abbott, G., \& Barnett, L. M. (2019). The new version of the pictorial scale of Perceived Movement Skill Competence in Spanish children: Evidence of validity and reliability. RICYDE. Revista internacional de ciencias del deporte. 55(15), 35-54.

https://doi.org/10.5232/ricyde2019.05503

\section{Introduction}

U nderstanding motor skill competence (MC) in children is not only of theoretical interest but also of importance for Physical Education (PE) teaching and training in practice settings. MC can be considered as a person's ability to execute different motor acts, including coordination of fine and gross motor skills that are necessary to everyday tasks (Henderson \& Sugden, 1992). According to the current Spanish Law of Education in Primary School (Spanish Royal Decree, 2014), the main goal of PE is to enhance children's physical literacy and $\mathrm{MC}$. MC is considered as the integrative knowledge, procedures, attitudes and feelings linked to the fundamental motor behaviour. The importance of including $\mathrm{MC}$ in the learning process is evidenced by the existence of an entire specific block of contents (out of five) related to fundamental movement skills (FMS) (i.e., Block 2. Motor skills, coordination and balance. Activities in the natural environment). FMS would refer to an observable goaloriented, voluntary movement task of one or more of the body parts commonly grouped as locomotor, manipulative and stability skills. MC is a broad concept which encompasses FMS (Gallahue, Ozmun \& Goodway, 2012). For the acquisition of this main goal, PE teachers must not only organize the contents in theoretical and practice lessons but also, they must promote critical attitudes so that the pupils understand perceptual, emotive and cognitive aspects related to motor tasks and derived feelings (Spanish Royal Decree, 2014). As a result, motor behaviours such as perception, interpretation, decision and evaluation of motor tasks must be implicit in the learning process.

Despite the formulation of the educational law, perceived physical competence is not described explicitly in the aforementioned PE curricula, even though both are conceptualised theoretically as being relevant to children and adolescents' health (Babic et al., 2014; Robinson et al., 2015; Stodden et al., 2008). Recently, in a longitudinal study Utesch, Dreiskämper, Naul, and Geukes (2018) confirmed that scores on perceived physical competence as well as levels of motor competence were positively associated with physical activity one year later for all children (linear additive effect). In this study a so-called agreement (or fit/congruence) effect between actual MC and the associated physical selfconcept was found. On the contrary, children's underestimation of one's own MC leads to lower future physical activity levels. That is, compared to higher values on each factor observed in an isolated fashion, the more accurate motor self-perceptions, the higher physical activity levels were one year later (Utesch et al., 2018 ".

A subdomain of perceived physical competence is perceived $\mathrm{MC}$, which refers to the perception of ability in FMS such as running, balance, catching, throwing or striking (Stodden et al., 2008). It is conceivable that perceived MC might also influence children's health trajectory (Robinson et al., 2015) by promoting physical activity in youth (Babic et al., 2014). In addition, it is well known that according to gender, boys are more physically active than girls (Nader et al., 2008) and more MC - particularly in ball skills (Barnett, Lai, et al., 2016). Thus, when the research question is focused on the effect of gender on perceived MC, boys report higher ball skills than girls (Estevan, Molina-García, Abbott, et al., 2018; Estevan, Molina-García, Bowe, et al., 2018; Liong et al., 2015).

Due to growing research interest regarding how children's perceived MC relates to actual $\mathrm{MC}$, and the collective impact of these factors on adolescents' engagement in PA and sports (e.g., Barnett, Morgan, Van Beurden, Ball, \& Lubans, 2011; Logan, Kipling Webster, Getchell, Pfeiffer, \& Robinson, 2015; Stodden et al., 2008; Utesch et al., 2018), there has been an increased focus in analysing the nature of the instruments for assessing actual and 
Estevan, I.; Molina-García, J.; Queralt, A.; Bowe, S. J.; Abbott, G., \& Barnett, L. M. (2019). The new version of the pictorial scale of Perceived Movement Skill Competence in Spanish children: Evidence of validity and reliability. RICYDE. Revista internacional de ciencias del deporte. 55(15), 35-54.

https://doi.org/10.5232/ricyde2019.05503

perceived MC. Taking into account that children's cognitive development may interfere their capability to make real judgements about their self (Harter, 1982), several proposals were suggested by Harter (Harter, 2012; Harter \& Pike, 1984) to guarantee the appropriate structure of the instruments. That is, creating pictorial scales, trying to reduce the tendency for children to give socially desirable responses, and having the ability to provide appropriate number of choices per item (e.g., two choices instead of four).

Another issue to be highlighted is the importance of using scales that match assessment of perceived and actual MC (Barnett, Vazou, et al., 2016; McGrane, Belton, Powell, Woods, \& Issartel, 2016). This means that for assessing children and adolescents' perceived MC, it is proposed that perception items align to the actual MC. MC assessment is either product- or a process-oriented; a qualitative and quantitative approach, respectively. Even though productoriented assessments are more common in the study of associations between actual and perceived MC (D’Hondt, Deforche, De Bourdeaudhuij, \& Lenoir, 2009; True, Brian, Goodway, \& Stodden, 2017), no product-oriented instrument specifically assesses similar motor tasks in actual and perceived MC. On the contrary, a well-known and valid processoriented instrument for assessing proficiency in actual MC in childhood in many different countries and cultures (Aalizadeh, Mohamadzadeh, \& Hosseini, 2014; Barnett, Ridgers, Zask, \& Salmon, 2015; Capio, Eguia, \& Simons, 2016; Freitas et al., 2015; Kim, Kim, Valentini, \& Clark, 2014; O’Brien, Belton, \& Issartel, 2016; Valentini, 2012) is the Test of Gross Motor Development (TGMD) (Ulrich, 2000).

The TGMD was utilized by Barnett et al. (Barnett, Vazou, et al., 2016; Barnett, Ridgers, Zask, et al., 2015) as a reference to develop a new scale for assessing perceived MC in children, the pictorial scale of Perceived Movement Skill Competence (PMSC). Originally, the PMSC was developed by including the same twelve motor tasks than in the TGMD second version (Ulrich, 2000) and adding six new active play skills. That is, the PMSC was composed by three subscales that includes 18 motor tasks: a) the six motor tasks of locomotion (e.g., run, gallop and slide), b) the six object control skills (e.g., overarm throw, bounce and kick a ball), and c) the six active play skills (e.g., swimming and climbing). Overall, this scale has acceptable reliability and validity in different child samples from Australia (Barnett, Vazou, et al., 2016; Barnett, Ridgers, \& Salmon, 2015; Barnett, Robinson, Webster, \& Ridgers, 2015), Brazil (Valentini et al., 2016), Portugal (Lopes et al., 2016) and Spain (Estevan, Molina-García, Abbott, et al., 2018). Although it is important to note the active play subscale did not emerge as a distinct factor in samples from Europe such as Portugal (Lopes et al., 2016) and Spain (Estevan, Molina-García, Abbott, et al., 2018).

Recently, a new third version of the TGMD has been proposed (Webster \& Ulrich, 2017). Concurrently, a new aligned version of the PMSC has also been developed (Johnson, Ridgers, Hulteen, Mellecker, \& Barnett, 2016). The new version reformulates some motor tasks: the leap and underhand roll skills were eliminated and the skip, one-hand forehand strike, and underhand throw were added. Currently the PMSC aligned with the TGMD third version (TGMD-3) integrates 19 items: six locomotor skills (i.e., run, gallop, skip, hop, slide, \& jumping forward), seven object control skills instead of six (i.e., strike with two hands, strike with one hand, stationary dribble, catch, kick, overhand throw \& underhand throw) and the same six active play skills.

To date the only validated versions of the PMSC aligned to the TGMD-3 are for Chinese (Diao, Barnett, Estevan, Dong, \& Li, 2018) and Greek children (Venetsanou, Kossyva, Valentini, Afthentopoulou, \& Barnett, 2018); even the English version has not yet been validated. Hence, the main purpose of this study was to examine the reliability and construct 
Estevan, I.; Molina-García, J.; Queralt, A.; Bowe, S. J.; Abbott, G., \& Barnett, L. M. (2019). The new version of the pictorial scale of Perceived Movement Skill Competence in Spanish children: Evidence of validity and reliability. RICYDE. Revista internacional de ciencias del deporte. 55(15), 35-54.

https://doi.org/10.5232/ricyde2019.05503

validity of the PMSC aligned to the TGMD-3 in a sample of Spanish children. Furthermore, a second aim was to analyse the validity of the PMSC and children's perceived MC according to children's gender. It is hypothesized that the new version of the Spanish PMSC will fit a two-factor model (i.e. object control and locomotor but not the active play), and boys will report higher perceived MC (specifically in ball skills) than girls.

\section{Methods}

\section{Participants}

Data for the current study were obtained from participants who are in the second year of a three year longitudinal study. Children were recruited originally via convenience sampling in 2016, and at this time the first version of the PMSC was administered and validated in 247 children (Estevan, Molina-García, Abbott, et al., 2018). In 2017, additional children were recruited to enlarge the sample resulting in a total of 366 children who had written parental or guardian consent to participate (consent rate of 85.4\%). Five children were excluded leaving 361 typically developing children $(55.7 \%$ boys $)$ with a mean age of 9.4 years $(S D=1.9)$ with complete and valid data. Just under a third of the current sample $(29 \%, 106$ out of 361 children) completed the first version of the PMSC in year 1.

Children were included in data analyses if they: (i) were between 4 and 11 years-old; (ii) were in full-time enrolment in a mainstream primary school at Valencian Community (Spain); (iii) had Spanish as the main language at school; (iv) had written informed consent provided by parent(s); (v) provided his/her own verbal assent to be involved. Children were excluded if they had had surgery in the last 3 months or had a physical, neurological, learning or intellectual disability. Children were recruited from one kindergarten and nine primary schools, and permission was obtained from the respective school Principal. Approval was obtained from The Institutional Review Board of the University (IRB code H1446557620395).

\section{Procedure}

\section{Back-translation}

The pictorial instrument designed by Dr. Lisa Barnett to assess perceived MC in children, was translated to Spanish following a back-translation process (i.e., English-Spanish-English) by two independent English specialist translators. These back translations were read by two authors (they also participated in the validity of the first version of the PMSC that is aligned with the TGMD-2) who suggested language adjustment to better reflect the intention in the three new motor tasks. The adjustments basically aimed to reflect the movement skills appropriately. A final translated and edited score sheet was developed. No more changes were made.

\section{$\underline{\text { Instrument }}$}

The original English second version of the PMSC (Johnson et al., 2016) assesses children's perceived motor skill competence by thirteen pictographic tasks (see Figure 1); matched to the thirteen FMS in the TGMD version 3 (Webster \& Ulrich, 2017). Subsequently, six active play skills were include for a thorough comprehension of the assessment of children's perceive MC (Barnett, Vazou, et al., 2016). The perception in each skill is rated from 1 to 4 , (with 4-points meaning high perception) using a double dichotomy process (i.e., firstly children are required to choose between the picture depicting a child who is competent in a skill and the picture depicting a child who is not so competent in a skill. Secondly, children 
are required again to choose between two choices: the two options for the 'competent' picture were 'really good at...' (assigned a score of 4-points) or 'pretty good at...' (3-points), while the options for the 'not so competent' picture were 'sort of good at...' (2-points) or 'not that good at...' (1-point). The score range for the total scale was 19-76, with subscales ranged 728 in ball skills, 6-24 in locomotion, and active play.

\section{Pretty good at the skill}

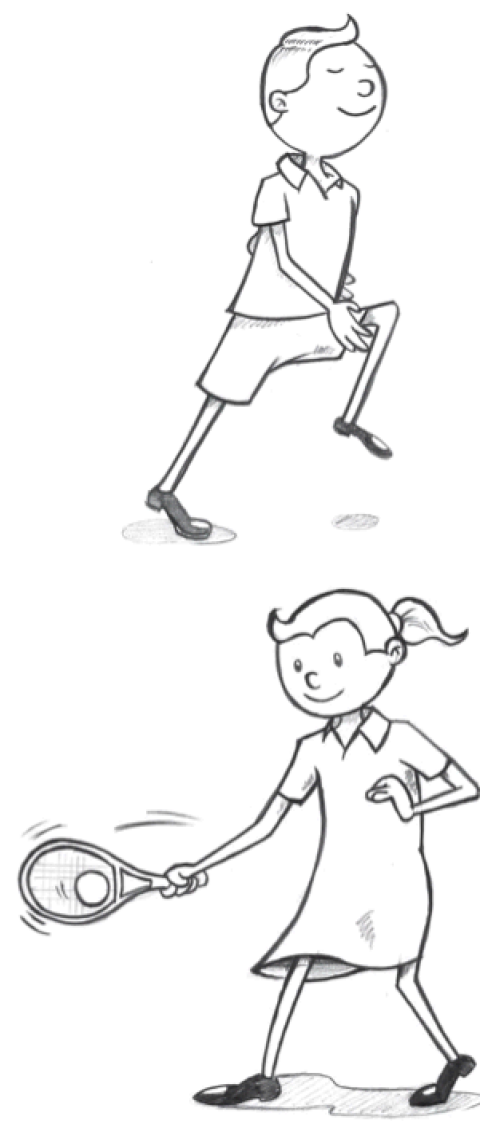

\section{Not very good at the skill}
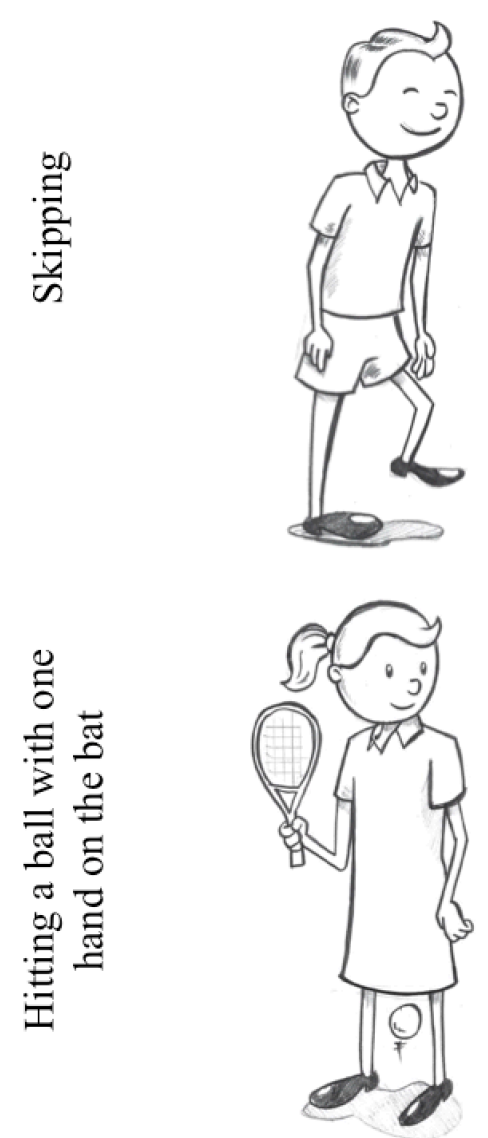

Figure 1. Example of the graphical description of two items in the second version of the pictorial scale of Perceived Movement Skill Competence

\section{Protocol}

In line with previous procedures in the validation of PMSC (Estevan, Molina-García, Abbott, et al., 2018), in order to avoid risk of bias (i.e., providing appropriate instructions with no feedback regarding their choice of skill level), research assistants completed a training of $4 \mathrm{~h}$ (on two different days) involving examples with children. Research assistants who conducted data collection were specialists in teaching Physical Education in primary school. The data collection was carried out in the schools with an administration time per child around 15-18 min. A random sample of 260 children was assessed twice to determine test-retest reliability, that is, one week after the first assessment the children were reassessed.

Prior to administration of the scale, every child received a video demonstration of each skill and was allowed to perform it. No feedback on performance was reported during these familiarization trials. Then, following the instructions of the English original scale (Barnett, Vazou, et al., 2016) the questionnaire was administered: children were initially asked if they had tried the skill previously. If they said yes, they were instructed to choose which picture 
Estevan, I.; Molina-García, J.; Queralt, A.; Bowe, S. J.; Abbott, G., \& Barnett, L. M. (2019). The new version of the pictorial scale of Perceived Movement Skill Competence in Spanish children: Evidence of validity and reliability. RICYDE. Revista internacional de ciencias del deporte. 55(15), 35-54.

https://doi.org/10.5232/ricyde2019.05503

they considered looked like them $\left(1^{\text {st }}\right.$ dichotomized choice $)$; then for their chosen picture they were asked again to choose their perceived competence ( $2^{\text {nd }}$ dichotomized choice). Children who had not the experience in any skill were asked for their recognition of the skill; when they did recognize the skill, they were then asked to rate what their perceived competence would be. Children who had not experience with that skill and who did not recognize the depicted task or verbal cues were supported with a demonstration by the research assistant. Every child recognized the motor tasks; only in some cases, galloping required an additional demonstration.

\section{$\underline{\text { Statistical Analyses }}$}

Descriptive analysis was conducted to report the percentage of children who had tried each FMS/Active play item, and the response (i.e. 'really good', 'pretty good' etc.) for each category.

Internal consistency was assessed using ordinal, polychoric correlation-based alphas, which provide a better estimate of reliability than Cronbach's alpha for binary and ordinal response scales (Gadermann, Guhn, \& Zumbo, 2012). As with Cronbach's alpha, ordinal alphas greater than 0.7 may be interpreted as showing acceptable internal consistency. The ordinal alpha values were calculated for the seven ball skills items, for the six locomotor skill items, and the six active play skills, in order to determine how well the different skill items measure each of the subtests. The reliability analysis was conducted using an $\mathrm{R}$ package: psych, which can be downloaded as part of the freely available software package R (R Core Team, 2016).

Test-retest reliability using the Intraclass Correlation Coefficient (ICC) was analysed in each subscale and the PMSC. Values above .90 were considered as excellent, between .89 and .70 as high, between .69 and .50 as moderate, and values below .49 were considered as poor (Munro, Visintainer, \& Page, 1986).

Construct validity was assessed using a Bayesian Structural Equation Modeling (BSEM) approach which has already been used in previous studies with the PMSC (Estevan, MolinaGarcía, Abbott, et al., 2018; Lopes et al., 2016). Each item has a four point ordinal response and the BSEM approach accounted for this in the modeling by treating the items as ordinal categorical rather than continuous variables. The BSEM approach allows cross loadings to be greater than zero, which reflects a real-world scenario. Also, BSEM better accommodates skewed distributions and performs better within small samples than does maximum likelihood SEM (Muthén \& Asparouhov, 2012).

The initial hypothesized theoretical model used the 19 items and three hypothesized factors (6-7-6 items): locomotion (run, gallop, hop, jump, step slide and skip), ball skills (throw upperarm, catch, kick, hit, bounce, throw underarm, and racket), and active play (cycle, scooter, board paddle, skate, swim, and climb). Each of the three factors were allowed to correlate because perceived motor competence among ball skills, locomotor and active play skills are not considered independent from each other. The 19 items were modelled as categorical variables.

A priori model was estimated for the three-factor models. When no evidence of adequate fit was obtained, a two-factor model was estimated i.e. 13 FMS skills (including both ball skills and locomotion). Models with non-informative priors (termed Model 1 and 3) and informative priors (cross-loadings) with zero-means and small variances equal to .01 (Model 2 and 4) (Fong \& Ho, 2013) were tested. Model estimation was performed using the Markov chain Monte Carlo algorithm and Gibbs Sampler with 60,000 iterations with the first 10,000 
Estevan, I.; Molina-García, J.; Queralt, A.; Bowe, S. J.; Abbott, G., \& Barnett, L. M. (2019). The new version of the pictorial scale of Perceived Movement Skill Competence in Spanish children: Evidence of validity and reliability. RICYDE. Revista internacional de ciencias del deporte. 55(15), 35-54.

https://doi.org/10.5232/ricyde2019.05503

iterations as burn-ins. More technical details of the BSEM approach are described in Asparouhov and Muthén (2012).

Model convergence was assessed with the potential scale reduction factor diagnostics, where a value of 1.10 or smaller is considered as evidence of convergence (Geldman, Carlin, Stern, $\&$ Rubin, 2004). The posterior predictive $p$-value and positive $95 \%$ credibility interval (Muthén \& Asparouhov, 2012), assessed model fit, where a low posterior predictive $p$-value $(p<.05)$ and a positive 95\% lower limit suggest a poor fitting model. The BSEM was carried out using MPlus 7 (Muthén \& Muthén, 2012). Data and scripts are available from the corresponding author upon request.

Mann-Whitney $U$ and Student $t$-test for independent samples were carried out for analysing gender differences between the identified subdomains and total PMSC data, respectively ( $p<$ $.05)$. The effect size of the differences was assessed by Cohen's $d$ (Cohen, 1988) for nonparametric and parametric conditions, respectively. Values of $d$ below .20, between .20-.49, between .50-.79 and above .80 correspond to trivial, small, moderate and large effects, respectively.

\section{Results}

Table 1 presents the children's perceptions of how good they were at each skill. It is noted that high percentages of children (more than $70 \%$ ) rated themselves pretty good or really good for FMS items such as cycling $(88.1 \%)$, riding a scooter $(75.1 \%)$, catching $(75.1 \%)$ and bouncing a ball (78.4\%), hopping (74.5\%), step slide $(78.9 \%)$ and swimming $(74.5 \%)$. Whereas, perceptions of how good they were for some skills, were not as high, such as hitting (43.5\%) and climbing (30.6\%). Table 2 presents the internal consistency and test-retest reliability of each subscale and the total PMSC.

The three-factor BSEM models with non-informative cross-loadings (Model 1) and informative cross-loadings (Model 2) were both poor fitting models (see Table 3). Examination of the factor loadings for model 1 (see Table 4) suggests that the active play factors had mostly weak loadings with only climb (.61) being above .6, whereas for Model 2, only swim (.76) and board paddle (.67) had strong loadings. On the other hand, the two-factor model with non-informative cross-loadings (Model 3) and informative cross-loadings (Model 4) were both adequate fitting models. The posterior predictive $p$-value was equal or greater than .05, respectively, in each model (which is desirable), though Model 4 (posterior predictive $p=.159$ ) presented slightly superior indexes. Factor loadings in Model 3 and 4 (see Table 5) for locomotion ranged from .52 to .78. Factor loadings for ball skills in Models 3 and 4 ranged from .56 to .74 .

Gender differences for the PMSC and subscales are shown in Table 6. Boys reported a higher perception of motor competence in locomotion $(p<.05)$, ball skills, and the PMSC $(p<.001)$ than girls. The effect size of the significant differences was large for ball skills and moderate for locomotion, the short FMS version (13 items) of the PMSC and the whole PMSC (19 items). 
Estevan, I.; Molina-García, J.; Queralt, A.; Bowe, S. J.; Abbott, G., \& Barnett, L. M. (2019). The new version of the pictorial scale of Perceived Movement Skill Competence in Spanish children: Evidence of validity and reliability. RICYDE. Revista internacional de ciencias del deporte. 55(15), 35-54.

https://doi.org/10.5232/ricyde2019.05503

Table 1. Percentage for each skill as to 'how good' children thought they were.

\begin{tabular}{|c|c|c|c|c|c|c|c|c|c|c|c|c|}
\hline \multirow[b]{2}{*}{ Subscales \& items } & \multicolumn{4}{|c|}{ Total sample $(n=361)$} & \multicolumn{4}{|c|}{ Boys $(n=201)$} & \multicolumn{4}{|c|}{ Girls $(n=160)$} \\
\hline & $\begin{array}{c}\text { Not too } \\
\text { good }\end{array}$ & $\begin{array}{c}\text { Sort of } \\
\text { good }\end{array}$ & Pretty good & Really good & Not too good & Sort of good & Pretty good & Really good & Not too good & Sort of good & Pretty good & Really gooc \\
\hline \multicolumn{13}{|l|}{ Locomotion } \\
\hline Run [Correr] & 5.0 & 19.4 & 41.0 & 34.6 & 2.5 & 15.4 & 36.3 & 45.8 & 8.1 & 24.4 & 46.9 & 20.6 \\
\hline Gallop [Galopar] & 6.9 & 27.4 & 37.4 & 28.3 & 6.0 & 26.4 & 39.8 & 27.9 & 8.1 & 28.8 & 34.4 & 28.8 \\
\hline Hop [Saltar a un pie] & 7.7 & 17.7 & 42.7 & 31.9 & 9.0 & 20.4 & 38.8 & 31.8 & 6.3 & 14.4 & 47.5 & 31.9 \\
\hline $\begin{array}{l}\text { Jump Forward [Salto } \\
\text { Horizontal] }\end{array}$ & 7.8 & 25.2 & 39.6 & 27.4 & 5.5 & 23.9 & 40.3 & 30.4 & 10.6 & 26.9 & 38.8 & 23.8 \\
\hline $\begin{array}{l}\text { Slide [Desplazamiento } \\
\text { lateral] }\end{array}$ & 3.3 & 17.7 & 35.7 & 43.2 & 3.0 & 12.9 & 36.8 & 47.3 & 3.8 & 23.8 & 34.4 & 38.1 \\
\hline $\begin{array}{l}\text { Skip [Avanzar saltando } \\
\text { mientras se eleva rodilla] }\end{array}$ & 8.3 & 24.4 & 41.8 & 25.5 & 6.0 & 23.9 & 42.8 & 27.4 & 11.3 & 25.0 & 40.6 & 23.1 \\
\hline \multicolumn{13}{|l|}{ Ball skills } \\
\hline Throw upperarm & & & & & & & & & & & & \\
\hline $\begin{array}{l}\text { [Lanzamiento por encima } \\
\text { de hombro] }\end{array}$ & 9.7 & 29.6 & 38.2 & 22.4 & 5.0 & 22.4 & 43.3 & 29.4 & 15.6 & 38.8 & 31.9 & 13.8 \\
\hline $\begin{array}{l}\text { Catch [Recepción a dos } \\
\text { manos] }\end{array}$ & 4.7 & 20.2 & 38.5 & 36.6 & 3.0 & 12.9 & 36.3 & 47.8 & 6.9 & 29.4 & 41.3 & 22.5 \\
\hline Kick [Chut a una pared] & 11.9 & 20.2 & 25.8 & 42.1 & 4.5 & 11.9 & 25.9 & 57.7 & 21.3 & 30.6 & 25.6 & 22.5 \\
\hline Hit [Bateo a dos manos] & 21.6 & 34.9 & 27.2 & 16.3 & 15.4 & 33.8 & 30.9 & 19.9 & 29.4 & 36.3 & 22.5 & 11.9 \\
\hline $\begin{array}{l}\text { Bounce [Bote de balón] } \\
\text { Throw underarm }\end{array}$ & 3.6 & 18.0 & 36.0 & 42.4 & 3.0 & 13.9 & 36.8 & 46.3 & 4.4 & 23.1 & 35.0 & 37.5 \\
\hline $\begin{array}{l}\text { [Lanzamiento por encima } \\
\text { de hombro] }\end{array}$ & 9.7 & 26.3 & 37.4 & 26.6 & 6.5 & 18.4 & 39.3 & 35.8 & 13.8 & 36.2 & 35.0 & 15.0 \\
\hline $\begin{array}{l}\text { Racket [Lanzamiento por } \\
\text { encima de hombro] }\end{array}$ & 9.7 & 23.8 & 35.2 & 31.3 & 4.0 & 17.9 & 38.8 & 39.3 & 16.8 & 31.3 & 30.6 & 21.3 \\
\hline \multicolumn{13}{|l|}{ Active Play } \\
\hline Cycle [Ir en bicicleta] & 5.5 & 6.4 & 33.8 & 54.3 & 4.0 & 3.5 & 30.8 & 61.7 & 7.5 & 10.0 & 37.5 & 45.0 \\
\hline Scooter [Ir en patinete] & 9.7 & 15.2 & 37.4 & 37.7 & 8.5 & 13.9 & 36.3 & 41.3 & 11.3 & 16.8 & 38.8 & 33.1 \\
\hline $\begin{array}{l}\text { Board paddle [Nadar } \\
\text { apoyado en tabla pequeña] }\end{array}$ & 16.1 & 29.9 & 29.6 & 24.4 & 14.9 & 29.4 & 33.3 & 22.4 & 17.5 & 30.6 & 25.0 & 26.9 \\
\hline Skate [Ir en patines] & 19.9 & 23.3 & 26.3 & 30.5 & 28.9 & 27.4 & 21.9 & 21.8 & 8.8 & 18.1 & 31.8 & 41.3 \\
\hline Swim [Nadar] & 6.1 & 19.4 & 38.8 & 35.7 & 5.0 & 18.4 & 42.3 & 34.3 & 7.5 & 20.6 & 34.4 & 37.5 \\
\hline Climb [Escalar] & 29.1 & 31.3 & 24.4 & 15.2 & 25.4 & 33.3 & 25.9 & 15.4 & 33.8 & 28.7 & 22.5 & 15.0 \\
\hline
\end{tabular}

Note1. Not too good = No muy bueno; Sort of good = Algo bueno; Pretty good = Bastante bueno; Really good = Muy bueno. Note2. Any item percentage totals not equal to $100 \%$ are due to rounding within the item categorie 
Estevan, I.; Molina-García, J.; Queralt, A.; Bowe, S. J.; Abbott, G., \& Barnett, L. M. (2019). The new version of the pictorial scale of Perceived Movement Skill Competence in Spanish children: Evidence of validity and reliability. RICYDE. Revista internacional de ciencias del deporte. 55(15), 35-54.

Table 2. Internal consistency and test-retest for each subscale and the PSMC.

\begin{tabular}{|c|c|c|c|c|}
\hline \multirow{2}{*}{ Subscales \& Scale } & \multicolumn{2}{|c|}{ Internal consistency } & \multicolumn{2}{|c|}{ Test-retest } \\
\hline & & Cronbach's alpha & $\mathrm{ICC}$ & $95 \% \mathrm{CI}$ \\
\hline Locomotion & .81 & $.77(.73, .81)$ & .93 & $(.91, .94)$ \\
\hline Ball skills & .84 & $.80(.76, .83)$ & .95 & $(.94, .96)$ \\
\hline Active play & .67 & $.61(.55, .68)$ & .84 & $(.80, .87)$ \\
\hline PMSCFMS (13 items) & .88 & $.84(.81, .87)$ & .95 & $(.94, .96)$ \\
\hline PMSC (19 items) & .89 & $.86(.84, .89)$ & .94 & $(.92, .95)$ \\
\hline
\end{tabular}

Note1. PMSC = Perception of Movement Skill Competence; FMS = Fundamental Movement Skills; 13 items only include those items related to locomotion and ball skills; $\mathrm{ICC}=$ Intraclass Correlation Coefficient; $\mathrm{CI}=$ Confidence Interval.

Note2. $\mathrm{a}=$ Ordinal alpha generated using R studio/SPSS; $\mathrm{b}=$ Cronbach's alphas and the 95\% CIs generated using R studio;

Table 3. Bayesian structural equation modeling results for the PMSC for the sample ( $\mathrm{n}=361)$.

\begin{tabular}{|c|c|c|c|c|c|c|}
\hline Model & Priors specification & $\begin{array}{l}\text { No. of free } \\
\text { parameters }\end{array}$ & $\begin{array}{l}2.5 \% \\
\text { PP limit }\end{array}$ & $\begin{array}{l}97.5 \% \\
\text { PP limit }\end{array}$ & PP p & $\begin{array}{l}\text { No. of Iterations } \\
\text { (Runtime) }\end{array}$ \\
\hline 1 & Three factor (6-7-6); non-informative & 79 & 64.30 & 175.39 & $<.0001$ & $60000(12 s)$ \\
\hline 2 & Three factor (6-7-6); informative cross-loadings & 117 & 24.46 & 143.35 & $<.0001$ & $60000(11 s)$ \\
\hline 3 & Two factor (6-7); non-informative & 53 & -17.55 & 67.67 & .093 & $60000(4 s)$ \\
\hline 4 & Two factor (6-7); informative cross-loadings & 66 & -21.28 & 58.36 & .159 & $60000(5 s)$ \\
\hline
\end{tabular}

Note. $\mathrm{PP}=$ posterior predictive; $\mathrm{s}=$ seconds. Informative priors on cross-loadings have a zero mean and variance of .01 . 
Estevan, I.; Molina-García, J.; Queralt, A.; Bowe, S. J.; Abbott, G., \& Barnett, L. M. (2019). The new version of the pictorial scale of Perceived Movement Skill Competence in Spanish children: Evidence of validity and reliability. RICYDE. Revista internacional de ciencias del deporte. 55(15), 35-54.

https://doi.org/10.5232/ricyde2019.05503

\section{Discussion}

The development of instruments for assessing actual MC in children has been a prolific endeavour (Cools, Martelaer, Samaey, \& Andries, 2009) with a high diversity of tests following a product and/or a process-oriented assessment (Logan, Barnett, Goodway, \& Stodden, 2017). Nevertheless, the amount of appropriate scales to assess children's perceived MC is limited. In this line, the main purpose of this study was to examine the reliability and construct validity of the PMSC aligned to the TGMD-3 in a sample of Spanish children. The results of the current study for the Spanish version of the PMSC aligned to the TGMD-3 showed between high and excellent internal consistency (or moderate in the case of the subscale 'Active Play'), excellent test-retest reliability (or 'high' in the subscale 'Active Play') and adequate construct validity (albeit for the FMS items) for Spanish children. The only other two validations of this version of the PMSC in Chinese (Diao et al., 2018) and Greek children (Venetsanou et al., 2018) also found that the two-factor model of FMS fitted adequately which supports our findings. Having a new validated instrument for those from Spanish speaking countries provides an insight in the advance of the knowledge of perceived MC not only in Spain but also for countries in America and those wherein the population speaking Spanish is high. This is key for assessing in the future plausible differences in MC perception amongst children from different Ibero-American countries that requires the existence and use of validated scales (Estevan, Molina-García, Abbott, et al., 2018).

In addition to the factorial structure (construct validity) of the PMSC aligned to the TGMD-3, the results also support the previous structure of the PMSC aligned to the TGMD-2 (Estevan, Molina-García, Abbott, et al., 2018) wherein a two-factor model was evidenced as the model with an adequate fit (see Table 3). Both versions of the pictorial scale PMSC aligned with the TGMD-2 and TGMD-3 showed the existence of two appropriate subscales, the locomotive and object control/ball skills subscales (the denomination changed in the second and third version, respectively) assessing two of the typical types of FMS (Haywood \& Getchell, 2014), supporting the hypothesized structure suggested by Webster and Ulrich (2017) for the objective assessment in the TGMD. It must be noted that even though most of the children in this study were older than those involved in the previous validations of the PMSC the factorial structure fitted adequately with a two-factor model. For instance, the Chinese validation was conducted in children aged 4 to 11 (mean of 9.4) (Diao et al., 2018), and the Greek validation in children aged 5 to 9 (mean 7.4) (Venetsanou et al., 2018). Our results therefore provide evidence that the pictorial scales can work in children who are somewhat older than those normally recommended to use pictorial scales.

Factor loading in the locomotive domain showed the gallop was the lowest loading item, which is reflected also in that some children wanted an additional demonstration during the assessment. This was also found in our previous Spanish validation in which we studied the PMSC and alignment to the TGMD-2 (Estevan, Molina-García, Abbott, et al., 2018). It must be noted that close to one third of children were the same in both studies, which might contribute to the similar result. Whilst the lower understanding of this skill item may slightly affect the validity of the assessment as a whole, our results for the non-informative and informative cross-loading suggest an appropriate fit, with factor loading higher than 0.5 (see Table 5) for the two-factor model related to the FMS version of the PMSC (13 items). 
Estevan, I.; Molina-García, J.; Queralt, A.; Bowe, S. J.; Abbott, G., \& Barnett, L. M. (2019). The new version of the pictorial scale of Perceived Movement Skill Competence in Spanish children: Evidence of validity and reliability. RICYDE. Revista internacional de ciencias del deporte. 55(15), 35-54.

https://doi.org/10.5232/ricyde2019.05503

Table 4. Bayesian structural equation model factor loadings - three factor (6-7-6) models.

\begin{tabular}{|c|c|c|c|c|c|c|}
\hline \multirow[t]{2}{*}{ Item } & \multicolumn{3}{|c|}{$\begin{array}{l}\text { Model } 1 \text { - Three factor (6-7-6); non- } \\
\text { informative }\end{array}$} & \multicolumn{3}{|c|}{$\begin{array}{l}\text { Model } 2 \text { - Three factor }(6-7-6) \\
\text { informative cross-loadings }\end{array}$} \\
\hline & Locomotor & Ball skills & $\begin{array}{c}\text { Active } \\
\text { play }\end{array}$ & Locomotor & Ball skills & $\begin{array}{c}\text { Active } \\
\text { play }\end{array}$ \\
\hline Run & $.671 *$ & - & - & $.761 *$ & .007 & -.025 \\
\hline Gallop & $.528 *$ & - & - & $.515 *$ & .017 & .000 \\
\hline Hop & $.607 *$ & - & - & $.642 *$ & -.079 & .019 \\
\hline Jump & $.719 *$ & - & - & $.711 *$ & -.015 & .013 \\
\hline Slide & $.614 *$ & - & - & $.530 *$ & .080 & .007 \\
\hline Skip & $.762 *$ & - & - & $.765 *$ & -.024 & .012 \\
\hline Throw upperarm & - & $.705 *$ & - & -.046 & $.742 *$ & .001 \\
\hline Catch & - & $.694 \%$ & - & .002 & $.692 \%$ & -.002 \\
\hline Kick & - & $.675^{*}$ & - & .088 & $.620 \%$ & -.013 \\
\hline Hit & - & $.576 *$ & - & -.044 & $.591 *$ & .028 \\
\hline Bounce & - & $.615^{*}$ & - & -.023 & $.616^{*}$ & .011 \\
\hline Throw underarm & - & $.752 \%$ & - & .017 & $.740 *$ & .003 \\
\hline Racket & - & $.593 *$ & - & -.023 & $.607 *$ & .003 \\
\hline Cycle & - & - & $.541 *$ & .084 & .128 & $.384 *$ \\
\hline Scooter & - & - & $.660 *$ & .129 & .116 & $.417 *$ \\
\hline Board paddle & - & - & $.472 *$ & -.015 & -.035 & $.668 *$ \\
\hline Skate & - & - & $.308 *$ & .080 & -.043 & $.274 *$ \\
\hline Swim & - & - & $.418 *$ & -.126 & -.036 & $.764 *$ \\
\hline \multirow[t]{2}{*}{ Climb } & - & - & $.666 *$ & .379 & .117 & $.164 *$ \\
\hline & \multicolumn{3}{|c|}{ Factor correlations } & \multicolumn{3}{|c|}{ Factor correlations } \\
\hline Locomotor & - & & & - & & \\
\hline Ball skills & $.696 *$ & - & & $.705 *$ & - & \\
\hline Active play & $.794 *$ & $.788 *$ & - & $.550 *$ & $.637 *$ & - \\
\hline
\end{tabular}

Note. All items were considered ordinal categorical data. Bold values indicate major loadings. * All major loadings were statistically significant $(p$-value $<.001)$ with $95 \%$ credibility intervals that did not cover zero.

Cultural aspects can be implicit in the development of any scale for assessing perceived competence and might influence the validity in a particular country. In Spain, the application of the TGMD was criticized (Cenizo Benjumea, Ravelo Afonso, Morilla Pineda, Ramírez Hurtado, \& Fernández-Truan, 2016) because some of the skills utilized for assessing actual $\mathrm{MC}$ are not specific enough for the Spanish culture (i.e., hitting a ball with a bat seems of particular interest to baseball/softball both of which are not typical sports/games in Spain). As it has been noted previously, the FMS items in the PMSC are directly aligned to the TGMD. In the current study, in line with previous research in the field (Estevan, Molina-García, Abbott, et al., 2018), when children were asked which picture of hitting a ball is most like $\mathrm{him} / \mathrm{her}$, a large percentage considered themselves as "not too good" or "sort of good" (see Table 1) and this may be because they are not as familiar with this skill compared to other type of skills that are more typical of the Spanish culture, such as kicking or bouncing (Estevan, Molina-García, Abbott, et al., 2018). Hence, an important point that must be highlighted, is the fact that the PMSC seems to be culturally sensitive by recognising the children's preferences according to the cultural context of the study. 
Estevan, I.; Molina-García, J.; Queralt, A.; Bowe, S. J.; Abbott, G., \& Barnett, L. M. (2019). The new version of the pictorial scale of Perceived Movement Skill Competence in Spanish children: Evidence of validity and reliability. RICYDE. Revista internacional de ciencias del deporte. 55(15), 35-54.

https://doi.org/10.5232/ricyde2019.05503

Table 5. Bayesian structural equation model factor loadings - two factor (6-7) models.

\begin{tabular}{|c|c|c|c|c|}
\hline \multirow{2}{*}{ Item } & \multicolumn{2}{|c|}{$\begin{array}{l}\text { Model } 3 \text { - Two factor (6-7); non- } \\
\text { informative }\end{array}$} & \multicolumn{2}{|c|}{$\begin{array}{l}\text { Model } 4-\text { Two factor (6-7); } \\
\text { informative cross-loadings }\end{array}$} \\
\hline & Locomotor & Ball skills & Locomotor & Ball skills \\
\hline Run & $.678 *$ & - & $.582 *$ & .099 \\
\hline Gallop & $.523 *$ & - & $.504 *$ & .027 \\
\hline Hop & $.599 *$ & - & $.669 *$ & -.082 \\
\hline Jump & $.713 *$ & - & $.733 *$ & -.020 \\
\hline Slide & $.623 *$ & - & $.563 *$ & .078 \\
\hline Skip & $.765 *$ & - & $.781 *$ & -.019 \\
\hline Throw upperarm & - & $.708 *$ & -.017 & $.721 *$ \\
\hline Catch & - & $.685 *$ & .008 & $.676^{*}$ \\
\hline Kick & - & $.663 *$ & .043 & $.628 *$ \\
\hline Hit & - & $.559 *$ & -.017 & $.576 *$ \\
\hline Bounce & - & $.609 *$ & -.007 & $.617 *$ \\
\hline Throw underarm & & $.761 \%$ & .022 & $.738 *$ \\
\hline \multirow[t]{2}{*}{ Racket } & - & $.581 *$ & -.020 & $.601 \%$ \\
\hline & \multicolumn{2}{|c|}{ Factor correlations } & \multicolumn{2}{|c|}{ Factor correlations } \\
\hline Locomotor & - & - & - & - \\
\hline Ball skills & $.692 *$ & - & $.681 *$ & - \\
\hline
\end{tabular}

Note. All items were considered ordinal categorical data. Bold values indicate major loadings. * All major loadings were statistically significant $(p$-value $<.001)$ with $95 \%$ credibility intervals that did not cover zero.

Relevant to the cultural context, the third subscale in the PMSC, the 'Active Play skills' subscale, did not fit adequately in the sample under study. It is notable that 'Active Play skills' could be seen as a part of goal-directed movement patterns that directly and indirectly impact an individual's capability to be physically active and thus promote health not only in childhood but also across the lifespan (Hulteen, Morgan, Barnett, Stodden, \& Lubans, 2018). However, the addition of the 'Active Play skills' meant the whole PMSC (19 items) did not fit appropriately (see Table 3). Model 1 and Model 2 showed factor loading in at least three items of the 'Active Play' being lower than 0.5 each (see Table 4). This was also the case in our previous validation (Estevan, Molina-García, Abbott, et al., 2018). We still considered it is important to investigate validity of this subscale again, as more than two thirds of children in this analysis were different children to the previous investigation, and the children were also a year older, which might mean they had more experience with these play skills. 
Estevan, I.; Molina-García, J.; Queralt, A.; Bowe, S. J.; Abbott, G., \& Barnett, L. M. (2019). The new version of the pictorial scale of Perceived Movement Skill Competence in Spanish children: Evidence of validity and reliability. RICYDE. Revista internacional de ciencias del deporte. 55(15), 35-54.

https://doi.org/10.5232/ricyde2019.05503

Table 6. Descriptive (mean and standard deviation) and differential analyses of every subscale and PMSC according to gender.

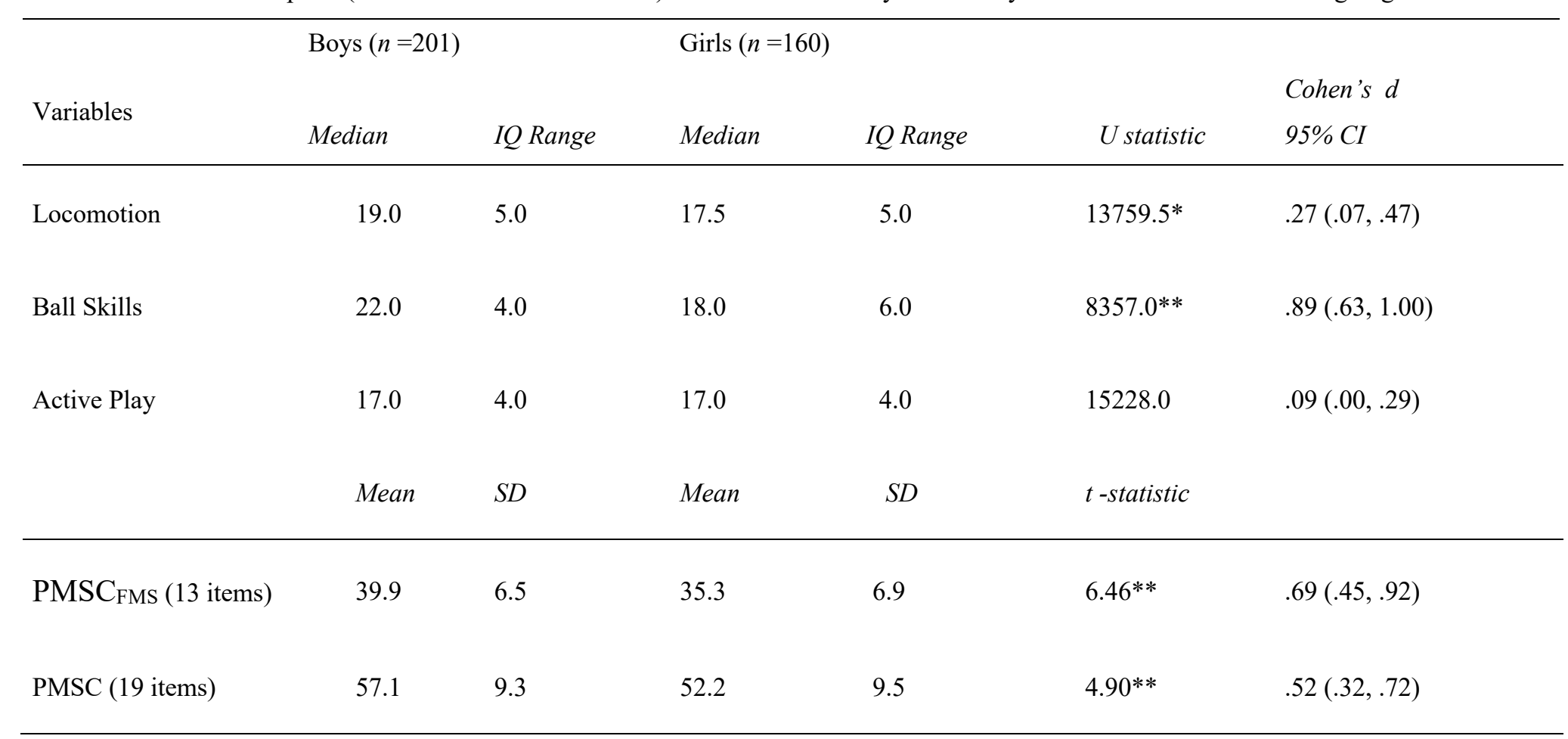

Note. For PMSC descriptive data are reported in terms of mean and standard deviation; PMSC = Perception of Movement Skill Competence; FMS = Fundamental Movement Skills; 13 items only include those items related to locomotion and ball skills. $* p<.05,{ }^{* *} p<.001$, Cohen's $d$ confidence intervals generated by bootstrapping. 
Estevan, I.; Molina-García, J.; Queralt, A.; Bowe, S. J.; Abbott, G., \& Barnett, L. M. (2019). The new version of the pictorial scale of Perceived Movement Skill Competence in Spanish children: Evidence of validity and reliability. RICYDE. Revista internacional de ciencias del deporte. 55(15), 35-54.

https://doi.org/10.5232/ricyde2019.05503

Nevertheless, our findings suggest that despite the 'Active Play' domain having strong loading in some items (e.g., cycling or scootering in Model 1, or swimming in Model 2), there are other items that do not seem to be adequate to Spanish children (Estevan, Molina-García, Abbott, et al., 2018). That is, there is a socio-cultural and geographical filter not only in actual MC (Hulteen et al., 2018) but also in perceived MC. Examples of this issue are the skate and the climb skills with low factor loadings. On the one hand, an interesting point regarding skating is the fact that young children noted the difference between in-line and roller skates. Whilst instructions specify that the image refers to either version of skating (i.e. how good are you at skating/blading?) the picture can only represent one version which could affect the children's perception. On the other hand, the climb can be also performed in diverse ways (e.g., vertical or diagonal/inclining climbing). In PE classes it is common to find creative learning environments wherein, for instance, PE teachers create different spaces in a gym with benches attached to the wall bars as a ramp, vertical mats, ropes attached to the wall having children the option of "climbing" with the help of the rope walking on the mat or the bench. These different frequent options might affect the children's perception according to their experience in any in these aforementioned educational environments. Moreover, even though the factor loading of other items such as the board paddle is relatively high, this might be an example of the plausible lack of cultural transference of this skill that may be specific to countries such as Australia where much of the population lives in coastal cities and is used to such specific skills. Although, the high factor loading might also reflect that we conducted this study in Spanish coastal areas mainly where children are used to swimming on the beach, which might lead them to recognize this skill appropriately. Nonetheless, we are not able to know whether another type of skill (e.g., treading water) would fit better than the board paddle. In order to have appropriate skills involving the 'Active Play' subscale with sociocultural transference, future studies should be conducted by changing the skills in this subscale, and designing and including typical skills, for instance those considered as foundational movement skills (Hulteen et al., 2018), characterized by the socio-cultural context and/or the geographical location of the country under study.

This is the second study to our knowledge that conducts confirmatory factor analyses in children's perceived motor competence (using this instrument) according to gender. The results of the current study indicated that boys perceived themselves as more competent than girls, which is in line with previous studies in the field (Barnett, Vazou, et al., 2016; Estevan, Molina-García, Bowe, et al., 2018; Liong et al., 2015). The different perceptions between boys and girls are also reflected when the BSEM are conducted for boys and girls separately (see Appendix). That is, slightly different factor loadings were found in boys and girls. However, the influence of gender in the validity of the scales does not seem to affect the twofactor model, as an adequate fit was found for the whole sample. The validation in Greek children (which only examined the FMS items) also found that both a one (only FMS) or two factor (object control and locomotor) model was acceptable for boys and girls (Venetsanou et al., 2018). Thus, independent of the sample under study, the PMSC can be applied in boys and girls from 4 to 11 years-old similarly.

When comparisons between boys' and girls' perceived MC are conducted according to the type of skill, the current study seems to confirm that boys tend to perceive themselves as more competent than girls in ball skills/object control skills (Barnett, Vazou, et al., 2016; Estevan, Molina-García, Abbott, et al., 2018; Liong et al., 2015) with large effects in ball skills, and moderate effects in locomotion skills. These differences might have transference for the participation in physical activity and actual MC across lifespan (Hulteen et al., 2018), which 
Estevan, I.; Molina-García, J.; Queralt, A.; Bowe, S. J.; Abbott, G., \& Barnett, L. M. (2019). The new version of the pictorial scale of Perceived Movement Skill Competence in Spanish children: Evidence of validity and reliability. RICYDE. Revista internacional de ciencias del deporte. 55(15), 35-54.

https://doi.org/10.5232/ricyde2019.05503

would confirm the sex role stereotypes that exist relative to physical activities. In Spain, it must be noted that the socio-cultural context seems to exert a clear effect on physical competence (Moreno-Murcia, Cervelló, Vera, \& Ruiz-Pérez, 2007); in this line, ball sports (e.g., football or basketball) are mainly culturally promoted to boys, meanwhile individual and harmonic activities (e.g., dance or ballet) are often stereotyped as for girls. As a result of these social contexts, boys' perception, compared with girls, is more linked to ball sports. These differences between genders may reflect underlying growth and developmental influences for boys and girls in this age range (Moreno Murcia et al., 2007). As a solution, it is recommended that not only PE teachers, but also the families (Estevan, Molina-García, Bowe, et al., 2018), promote the practice of both ball sports and individual and harmonic activities for both boys and girls.

Actually, the curricula for PE lessons (Spanish Royal Decree, 2014) establishes that PE teachers are encouraged to promote children's practice in a diversity of physical activities not only in the school but also in leisure time. Furthermore, it is also established that a high diversity of physical activities and games should be promoted in PE classes (Spanish Royal Decree, 2014). Recently, Hulteen et al. (2018) suggested that those individuals who perceive themselves as competent seem to be more willing to try and persist at new activities. These new experiences might enhance to further develop actual MC and hopefully physical activity. For instance, an individual with high self-concept, who played tennis as a child, may be more willing to try other striking/racquet activities (e.g., badminton, olympic frontenis, padel), despite never having played.

Considering these findings, PE teachers could use the PMSC to assess perceived motor development. That is, it could be good to know which pupils in primary school underestimate, accurately estimates or overestimates his/her actual MC (Utesch et al., 2018); with this information in mind, PE teachers could orient the teaching in an appropriate way by increasing, adjusting or decreasing the MC support according to their perceived $\mathrm{MC}$, respectively. For instance, in a case wherein a boy or a girl underestimates his/her actual MC, a PE teacher could promote and/or enhance the MC perception by providing appropriate strategies with positive implications in the future physical activity practice and weight status (Utesch et al., 2018).

Despite the benefits of using pictorial scales, such as the PMSC, specifically adapted to the children's cognitive characteristics and aligned to process-oriented MC test, some limitations should also might accompany the application of this scale. Firstly, considering the children's reports in every item had a higher frequency of the responses pretty or really good (i.e., three or four out of four points) compared to not too or sort of good, having a four-point scale might limit longitudinal studies by a ceiling effect. Secondly, due to the nature of crosssectional assessments, the acute and isolated application of this scale in children without considering their actual MC limits the assumptions derived from the results. As a result, it is recommended that not only cross-sectional studies in the field of children's MC are conducted but longitudinally with the assessment of both, actual and perceived MC. 


\section{Conclusion}

Perceived $\mathrm{MC}$ is an aspect of physical self-perception which has been conceptualized in theoretical models (Robinson et al., 2015; Stodden et al., 2008) with the aim to explain how actual and perceived MC drive children's physical activity levels. The current study provides evidence of the construct validity and reliability of the two-factor PMSC (Spanish version) aligned with the TGMD-3 in the locomotion, the ball skills and its short FMS version, with boys reporting higher than girls in every of the aforementioned subscales and scale. As a conclusion, we consider that the new version of the pictorial scale of PMSC is an appropriate instrument to measure the perceived MC in Spanish children both in boys and in girls.

\section{Acknowledgements}

For a thorough understanding of each of the skill items included in the form of the PMSC aligned with the TGMD-3, the authors recommend watching the following Youtube clip: https://www.youtube.com/watch?v=9WggHyZpXI0

\section{References}

Aalizadeh, B.; Mohamadzadeh, H., \& Hosseini, F. S. (2014). Fundamental Movement Skills among Iranian Primary School Children. Journal of Family \& Reproductive Health, 8(4), 155-159.

Asparouhov, T., \& Muthén, B. (2012). Multiple Group Multilevel Analysis. Mplus Web Notes, 16(15), 1-45.

Babic, M. J.; Morgan, P. J.; Plotnikoff, R. C.; Lonsdale, C.; White, R. L., \& Lubans, D. R. (2014). Physical activity and physical self-concept in youth: systematic review and meta-analysis. Sports Medicine, 44(11), 1589-1601.

https://doi.org/10.1007/s40279-014-0229-z

Barnett, L. M.; Lai, S. K.; Veldman, S. L. C.; Hardy, L. L.; Cliff, D. P.; Morgan, P. J.; ... Okely, A. D. (2016). Correlates of Gross Motor Competence in Children and Adolescents: A Systematic Review and Meta-Analysis. Sports Medicine, 46(11), 16631688.

https://doi.org/10.1007/s40279-016-0495-z

Barnett, L. M.; Morgan, P. J.; Van Beurden, E.; Ball, K., \& Lubans, D. R. (2011). A reverse pathway? Actual and perceived skill proficiency and physical activity. Medicine and Science in Sports and Exercise, 43(5), 898-904.

https://doi.org/10.1249/MSS.0b013e3181fdfadd

Barnett, L. M.; Ridgers, N. D., \& Salmon, J. (2015). Associations between young children's perceived and actual ball skill competence and physical activity. Journal of Science and Medicine in Sport, 18(2), 167-171.

https://doi.org/10.1016/j.jsams.2014.03.001

Barnett, L. M.; Ridgers, N. D.; Zask, A., \& Salmon, J. (2015). Face validity and reliability of a pictorial instrument for assessing fundamental movement skill perceived competence in young children. Journal of Science and Medicine, 18(1), 98-102. https://doi.org/10.1016/j.jsams.2013.12.004

Barnett, L. M.; Robinson, L. E.; Webster, E. K., \& Ridgers, N. D. (2015). Reliability of the Pictorial Scale of Perceived Movement Skill Competence in 2 Diverse Samples of Young Children. Journal of Physical Activity \& Health, 12(8), 1045-1051.

https://doi.org/10.1123/jpah.2014-0141 
Barnett, L. M.; Vazou, S.; Abbott, G.; Bowe, S. J.; Robinson, L. E.; Ridgers, N. D., \& Salmon, J. (2016). Construct validity of the pictorial scale of Perceived Movement Skill Competence. Psychology of Sport and Exercise, 22, 294-302. https://doi.org/10.1016/j.psychsport.2015.09.002

Capio, C. M.; Eguia, K. F., \& Simons, J. (2016). Test of gross motor development-2 for Filipino children with intellectual disability: validity and reliability. Journal of Sports Sciences, 34(1), 10-17. https://doi.org/10.1080/02640414.2015.1033643

Cenizo Benjumea, J. M.; Ravelo Afonso, J.; Morilla Pineda, S.; Ramírez Hurtado, J. M., \& Fernández-Truan, J. C. (2016). Diseño y validación de instrumento para evaluar coordinación motriz en primaria / Design and Validation of a Tool to Assess Motor Coordination in Primary. Revista Internacional de Medicina y Ciencias de la Actividad Física y del Deporte, 62(2016), 203-219. https://doi.org/10.15366/rimcafd2016.62.002

Cohen, J. (1988). Statistical power analysis for the behavioural sciences. Hillsdale, NJ: Lawrence Erlbaum.

Cools, W.; Martelaer, K. D.; Samaey, C., \& Andries, C. (2009). Movement skill assessment of typically developing preschool children: a review of seven movement skill assessment tools. Journal of Sports Science \& Medicine, 8(2), 154-168.

D'Hondt, E.; Deforche, B.; De Bourdeaudhuij, I., \& Lenoir, M. (2009). Relationship between motor skill and body mass index in 5- to 10-year-old children. Adapted Physical Activity Quarterly, 26(1), 21-37.

Diao, Y.; Barnett, L.; Estevan, I.; Dong, C., \& Li, J. (2018). Validity and Reliability of a Pictorial Instrument for Assessing Fundamental Movement Skill Perceived Competence in Chinese Children. Journal of Motor Learning and Development, 6(2), 1-27. https://doi.org/10.1123/jmld.2016-0082

Estevan, I.; Molina-García, J.; Abbott, G.; Bowe, S.; Castillo, I., \& Barnett, L. (2018). Evidence of Reliability and Validity for the Pictorial Scale of Perceived Movement Skill Competence in Spanish Children. Journal of Motor Learning and Development, 6(2), 127. https://doi.org/10.1123/jmld.2016-0065

Estevan, I.; Molina-García, J.; Bowe, S. J.; Álvarez, O.; Castillo, I., \& Barnett, L. M. (2018). Who can best report on children's motor competence: Parents, teachers, or the children themselves? Psychology of Sport and Exercise, 34, 1-9. https://doi.org/10.1016/j.psychsport.2017.09.002

Fong, T. C. T., \& Ho, R. T. H. (2013). Factor analyses of the Hospital Anxiety and Depression Scale: a Bayesian structural equation modeling approach. Quality of Life Research: An International Journal of Quality of Life Aspects of Treatment, Care and Rehabilitation, 22(10), 2857-2863.

https://doi.org/10.1007/s11136-013-0429-2

Freitas, D. L.; Lausen, B.; Maia, J. A.; Lefevre, J.; Gouveia, É. R.; Thomis, M.; ... Malina, R. M. (2015). Skeletal maturation, fundamental motor skills and motor coordination in children 7-10 years. Journal of Sports Sciences, 33(9), 924-934. https://doi.org/10.1080/02640414.2014.977935

Gadermann, A. M.; Guhn, M., \& Zumbo, B. D. (2012). Estimating Ordinal Reliability for Likert-Type and Ordinal Item Response Data: A Conceptual, Empirical, and Practical Guide. Practical Assessment, Research \& Evaluation, 17(3), 1-13.

Gallahue, D. L., Ozmun, J. C., \& Goodway, J. D. (2012). Understanding Motor Development: Infants, Children, Adolescents, Adults (7th ed.). New York: McGraw-Hill Education. 
Geldman, A.; Carlin, J. B.; Stern, H. S., \& Rubin, D. B. (2004). Bayesian Data Analysis (2nd ed.). Boca Raton, FL: Chapman \& Hall.

Harter, S. (1982). The Perceived Competence Scale for Children. Child Development, 53(1), 87-97. https://doi.org/10.2307/1129640

Harter, S. (2012). Self-Perception Profile for Children: Manual and Questionnaires. University of Denver.

Harter, S., \& Pike, R. (1984). The pictorial scale of perceived competence and social acceptance for young children. Child Development, 55(6), 1969-1982.

Haywood, K. M., \& Getchell, N. (2014). Life Span Motor Development (6th ed.). Champaing, IL: Human Kinetics.

Henderson, S., \& Sugden, D. (1991). Movement assessment battery for children. London: The Psychological Corporation.

Hulteen, R. M.; Morgan, P. J.; Barnett, L. M.; Stodden, D. F., \& Lubans, D. R. (2018). Development of Foundational Movement Skills: A Conceptual Model for Physical Activity Across the Lifespan. Sports Medicine, 1-8. https://doi.org/10.1007/s40279-018-0892-6

Johnson, T. M.; Ridgers, N. D.; Hulteen, R. M.; Mellecker, R. R., \& Barnett, L. M. (2016). Does playing a sports active video game improve young children's ball skill competence? Journal of Science And Medicine In Sport, 19(5), 432-436. https://doi.org/10.1016/j.jsams.2015.05.002

Kim, S.; Kim, M. J.; Valentini, N. C., \& Clark, J. E. (2014). Validity and reliability of the TGMD-2 for South Korean children. Journal of Motor Behavior, 46(5), 351-356. https://doi.org/10.1080/00222895.2014.914886

Liong, G. H. E.; Ridgers, N. D., \& Barnett, L. M. (2015). Associations between skill perceptions and young children's actual fundamental movement skills. Perceptual and Motor Skills, 120(2), 591-603.

https://doi.org/10.2466/10.25.PMS.120v18x2

Logan, S. W.; Barnett, L. M.; Goodway, J. D., \& Stodden, D. F. (2017). Comparison of performance on process- and product-oriented assessments of fundamental motor skills across childhood. Journal of Sports Sciences, 35(7), 634-641. https://doi.org/10.1080/02640414.2016.1183803

Logan, S. W.; Webster, K. E.; Getchell, N.; Pfeiffer, K. A., \& Robinson, L. E. (2015). Relationship Between Fundamental Motor Skill Competence and Physical Activity During Childhood and Adolescence: A Systematic Review. Kinesiology Review, 4(4), 416-426.

https://doi.org/10.1123/kr.2013-0012

Lopes, V. P.; Barnett, L. M.; Saraiva, L.; Gonçalves, C.; Bowe, S. J.; Abbott, G., \& Rodrigues, L. P. (2016). Validity and reliability of a pictorial instrument for assessing perceived motor competence in Portuguese children. Child: Care, Health and Development, 42(5), 666-674.

https://doi.org/10.1111/cch.12359

McGrane, B.; Belton, S.; Powell, D.; Woods, C. B., \& Issartel, J. (2016). Physical selfconfidence levels of adolescents: Scale reliability and validity. Journal of Science and Medicine in Sport, 19(7), 563-567. https://doi.org/10.1016/j.jsams.2015.07.004 
Moreno Murcia, J. A.; Cervelló, E.; Vera, J. A., \& Ruiz-Pérez, L. M. (2007). Physical SelfConcept of Spanish Schoolchildren: Differences by Gender, Sport Practice and Levels of Sport Involvement. Journal of Education and Human Development, 1(2). Recuperado a partir de:

http://www.scientificjournals.org/journals2007/articles/1180.pdf

Munro, B. H.; Visintainer, M. A., \& Page, E. B. (1986). Statistical Methods for Health Care Research. Philadelphia, PH: J.B. Lippincott.

Muthén, B., \& Asparouhov, T. (2012). Bayesian structural equation modeling: a more flexible representation of substantive theory. Psychological Methods, 17(3), 313-335. https://doi.org/10.1037/a0026802

Muthén, L. K., \& Muthén, B. (2012). Mplus user's guide. Los Angeles, CA: Muthen \& Muthen.

Nader, P. R.; Bradley, R. H.; Houts, R. M.; McRitchie, S. L., \& O'Brien, M. (2008). Moderate-to-vigorous physical activity from ages 9 to 15 years. JAMA, 300(3), 295305.

https://doi.org/10.1001/jama.300.3.295

O'Brien, W.; Belton, S., \& Issartel, J. (2016). Fundamental movement skill proficiency amongst adolescent youth. Physical Education and Sport Pedagogy, 21(6), 557-571. https://doi.org/10.1080/17408989.2015.1017451

R Core Team. (2016). R: A Language and Environment for Statistical Computing. Vienna, Austria: R Foundation for Statistical Computing. Retrieved from http://www.Rproject.org

Robinson, L. E.; Stodden, D. F.; Barnett, L. M.; Lopes, V. P.; Logan, S. W.; Rodrigues, L. P., \& D'Hondt, E. (2015). Motor Competence and its Effect on Positive Developmental Trajectories of Health. Sports Medicine, 45(9), 1273-1284. https://doi.org/10.1007/s40279-015-0351-6

Spanish Royal Decree (2014). Por el que se establece el currículo básico de la Educación Primaria (whereby the curriculum basis of Primary Education is established), 126 Boletín Oficial del Estado § 52 § 1.

Stodden, D. F.; Goodway, J. D.; Langendorfer, S. J.; Roberton, M. A.; Rudisill, M. E.; Garcia, C., \& Garcia, L. E. (2008). A Developmental Perspective on the Role of Motor Skill Competence in Physical Activity: An Emergent Relationship. Quest, 60(2), 290306. https://doi.org/10.1080/00336297.2008.10483582

True, L.; Brian, A.; Goodway, J.; \& Stodden, D. (2017). Relationships Between Productand Process-Oriented Measures of Motor Competence and Perceived Competence. Journal of Motor Learning and Development, 5(2), 319-335. https://doi.org/10.1123/jmld.2016-0042

Ulrich, D. A. (2000). Test of Gross Motor Development-2. Austin, TX: Prod-Ed.

Utesch, T.; Dreiskämper, D.; Naul, R., \& Geukes, K. (2018). Understanding physical (in-) activity, overweight, and obesity in childhood: Effects of congruence between physical self-concept and motor competence. Scientific Reports, 8(1), 5908. https://doi.org/10.1038/s41598-018-24139-y

Valentini, N. C. (2012). Validity and reliability of the TGMD-2 for Brazilian children. Journal of Motor Behavior, 44(4), 275-280. https://doi.org/10.1080/00222895.2012.700967 
Estevan, I.; Molina-García, J.; Queralt, A.; Bowe, S. J.; Abbott, G., \& Barnett, L. M. (2019). The new version of the pictorial scale of Perceived Movement Skill Competence in Spanish children: Evidence of validity and reliability. RICYDE. Revista internacional de ciencias del deporte. 55(15), 35-54.

https://doi.org/10.5232/ricyde2019.05503

Venetsanou, F.; Kossyva, I.; Valentini, N.; Afthentopoulou, A.-E., \& Barnett, L. (2018). Validity and Reliability of the Pictorial Scale of Perceived Movement Skill Competence for Young Greek Children. Journal of Motor Learning and Development, 6(2), 1-22. https://doi.org/10.1123/jmld.2017-0028

Webster, E. K., \& Ulrich, D. A. (2017). Evaluation of the Psychometric Properties of the Test of Gross Motor Development-Third Edition. Journal of Motor Learning and Development, 5(1), 45-58.

https://doi.org/10.1123/jmld.2016-0003 